(154)

\title{
Food Preference of Endemic Sri Lanka Yellow-eared Bulbul (Pycnonotus penicillatus) in Breeding and Non-breeding seasons at Horton Plains National Park
}

\author{
Chandrasiri P.H.S.P., Mahaulpatha W.A.D.* \\ Department of Zoology, University of Sri Jayewardenepura, Sri Lanka \\ *spchandrasiri@gmail.com
}

\begin{abstract}
Food preference of Sri Lanka Yellow-eared Bulbul (Pycnonotus penicillatus) in Breeding and non-breeding seasons was studied at the montane cloud forests of Horton Plains National Park, situated in the highland plateau of the central highlands, from September 2015 to July 2017 in three consecutive days per month. P. penicillatus is an endemic near threatened species. They have two breeding seasons; February-May and August-October. Direct foraging observations and faecal sample analysis methods were used to collect data. Four mist nets (3x6 $\mathrm{m}^{2} / 25 \mathrm{~mm}$ mesh size) were allocated from 0600 to $1800 \mathrm{~h}$ in mist netting days. Droppings of the bird was later scraped individually into collecting bottles with $70 \%$ alcohol and stored. Some droppings were collected in the field. These samples were taken to the laboratory for further analysis. The samples were first divided into two main parts as high plant matter samples and high insect matter samples by visually observing the faecal matter. 'High plant matter' faecal samples were directly analysed. High insect matter samples were analysed after using standard protocols. The seeds of the plants were identified by the keys and, insect parts were identified to order level by using insect identification guides. Within the study period there were 1,903 field observations and 50 faecal sample analysis were performed. In the breeding season $87.9 \%$ of the feeding observations were consisted with 18 species of plants and remain $12.1 \%$ was consisted with animal parts from one Pheretima species, thirteen species of insects, including three species from Order Diptera, three species from Order Lepidoptera, two species from Order Coleoptera, three species from Order Hymenoptera, one species from Order Blattodea and one species from Order Hemiptera. In the non-breeding season $98.1 \%$ of the feeding observations were consisted with 15 species of plants and other $1.9 \%$ was completed with four species of animal parts, including one species from Order Diptera, one species from Order Lepidoptera and two species from Order Coleoptera. Present study revealed that $P$. penicillatus preferred more animal food items in the breeding season, possibly to secure the extra energy requirements during their breeding season. These studies will be important for conservation of $P$. penicillatus, by using speciesspecific conservation plans in the future.
\end{abstract}

Keywords: Sri Lanka Yellow-eared Bulbul, Endemic birds, Horton Plains National Park, Food preference, Breeding and non-breeding seasons

Proceedings of the $22^{\text {nd }}$ International Forestry and Environment Symposium 2017 of the Department of Forestry and Environmental Science, University of Sri Jayewardenepura, Sri Lanka 